\title{
Calendula officinalis Seed oil
}

National Cancer Institute

\section{Source}

National Cancer Institute. Calendula officinalis Seed oil. NCI Thesaurus. Code C72194.

The oil extracted from the seeds of Calendula officinalis. Calendula officinalis seed oil is used for its anti-inflammatory properties. 